\title{
ON THE RATE OF MORTALITY AT THE PERIOD OF EARLY MANHOOD.
}

\section{To the Editor of the Journal of tho Institute of Actuaries.}

SIR,-In an ingenious letter from Mr. Makeham in your last number on the subject of extra risks, that gentleman in discussing the effect of making arbitrary additions to the age of the person whose life is assured, uses the words "Mr. Bailey's theory." Will you allow me a little space, not to gainsay Mr. Makebam's conclusions, with which I am well disposed to agree, but to explain that on the subject of the law of mortality I have no theory to maintain. Some years ago, during the progress of some investigations on this subject, I arrived at the conclusion that Gompertz's theory failed at the period of early manhood. Or to speak more specifically,-that so far from it being uniformly true that the "power to oppose destruction" in the human frame loses equal proportions in equal times, there is abuudant evidence to prove that the rate of mortality during the quinquennial period from 20 to 24 years of age is greater than in the next succeeding period from 25 to 29 .

As it may interest some of your readers to know on what grounds this conclusion was founded, the evidence is here subjoined, not without hopes that its publication may tend to elicit further information on the subject.

Arunual Mortality per Cent.

\begin{tabular}{|c|c|c|}
\hline Table. & Age 20 to 24. & Age 25 to 29 . \\
\hline 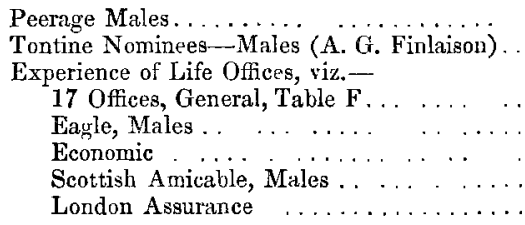 & $\begin{array}{r}1 \cdot 10 \\
1 \cdot 42 \\
\cdot 89 \\
1 \cdot 16 \\
.98 \\
.72 \\
.93\end{array}$ & $\begin{array}{l}76 \\
.78 \\
.65 \\
.70 \\
.63\end{array}$ \\
\hline
\end{tabular}

In Mr. Fox's paper "On the Vital Statistics of the Society of Friends," Statistical Journal, Vol. 22, page 220, the rate of mortality is given for decennial periods of life; and it appears that while the rate from 20 to 30 is $\cdot 881$, for the following decade it is 782 only, in that Society.

It seems to me that this evidence is too strong to be impeached; and yet in the graduated tables that have been formed from these observations the peculiarity has been made to disappear.

$$
\begin{aligned}
& \text { I am, Sir, } \\
& \text { Your obedient servant, }
\end{aligned}
$$

London Assurance,

ARTHUR H. BAILEY.

7, Royal Exchange, 9th March, 1868. 